\title{
Short Term Planning and Scheduling For Gasoline Blending in Oil Refineries
}

\author{
Faisal G. Zhqiar*Dr.Prof. Alla-EIdine Hassan** \\ Dr.Assist Prof. Lamyaa M. Dawood** \\ *Iraq Oil Ministry: Midland Refineries Company \\ **UOT Production Engineering and Metallurgy department Iraq. Baghdad.
}

\section{$\underline{\text { Abstract }}$}

$\mathrm{P}_{\text {roduct blending is an }}$ important optimization task that is encountered in the operation and scheduling of important industrial plants like petroleum refineries. The key objective of blending is to mix various intermediate products to achieve desired properties and quantities of products with minimum cost. There are uncertain parameters which make it very difficult to attain the optimum allocation of available resources. Consequently, there is a need to develop computational optimization techniques to tackle the blending issues.

In this research the main objective is to propose an approach to solve product blending issue in an optimum way. The blending problem can be formulated as an optimization where its objective is to maximize net profit while determining the optimal allocation of intermediate streams to produce optimum production mix of final products.

The proposed approach is introduced for integrating short term planning and scheduling for product blending. Two mathematical models have been proposed. The first model deals with planning issue for product blending and the results are regarded as production guidelines. In the second scheduling model, scheduling will treat the production guidelines to verify optimum allocation for available resources. The approach was applied to different real time case studies form Midland Refineries 
Company, and the results show the efficiency and flexibility of this approach to solve the different case studies. Also minimize lead time from 72 to $24 \mathrm{hr}$ in the second case according to reduction in re-blend process, in addition to minimize production cost depending on optimum allocation for available resources. The last case study which is a complicated one, were WIN QSB version 1.00 software is utilized. The results gained after 0.031 second CPU time for planning level and 3.375 second CPU time for scheduling level. This is considered as an advantage to the model.

\section{Introduction}

\section{The petroleum refining} industry is an important kind of process industries which are vital to the national economy in any state in the world [1]. Oil refining is regarded as the most complex chemical industries that may involve different and many complicated processes with various possible connections. Challenges facing oil refining industries are designated as surplus refining capacity, and the increase in crude oil prices causing decrease in profit margins. These challenges are accompanied by the impact of global market competition and strict environmental regulations [2and3]. In order to compete successfully in international markets and with global competition, oil refineries are increasingly concerned with improving the planning and scheduling of their operations to achieve better economic performance. Any benefits from improved control optimization of processes upstream will be useless if the final blending step is sub-optimal [4]. Therefore, optimum recipe for blended product is considered as a key question in the refineries, and become the center of technology innovations [5]. The short-term scheduling problem is still one of the most challenging problems in operational research due to the complexity of the scheduling 
operations and the corresponding process models [1, 6and7].

Product blending and distribution system scheduling are important parts of refinery optimisation, because they are strongly related to ever-changing market demands and prices. Gasoline Blending process is generally agreed as being the most important and complex problem. Its importance comes from the fact that gasoline is a profitable product for refinery where (60-70\%) of a typical refinery's total revenue comes from the gasoline sale. On the other hand, the complexity arises from the large number of product demands and quality specifications for each final product, as well as the limited number of available resources that can be used to reach the production goals [8].Therefore, The goal of planning and scheduling in refineries is to maximize the profitability by choosing the best feed stocks, operating conditions, and schedules, while fulfilling product quantity and quality objectives that are consistent with marketing commitments[5].

Scheduling of blending process has a large potential to provide a competitive benefit for oil refiners [3]. Significant cost savings and improved profits can be achieved through the planning and scheduling optimization of refinery operations [1].

\section{Problem Definition}

At the planning level, the effects of changeovers and daily inventories are neglected, and according to the uncertainty in these parameters, the determined solution at the planning level will be optimistic estimates that cannot be realized [5]. At the scheduling level the schedule may be infeasible or even if it was feasible schedule,

increasing the production cost may occur according to quantity and quality giveaway of the blended product that will be the cause of increase in lead time and product 
cost, consequently, the optimality of the planning solution cannot be ensured [7]. Therefore, developing methodology that can effectively short term production planning and scheduling in petroleum refineries is needed to verify the optimality.

The aim of this research is to develop a framework for short term planning and scheduling in petroleum refineries, by using mathematical model and sensitivity analysis to predict uncertain parameters. This framework consists of two levels. The planning level is the first, in which Linear Programming model (LP) or Linear Goal Programming if there are multi objectives (LGP) model are proposed. While the second level MILP model is proposed for scheduling issue. So the main objectives of this framework can be summarized as follows:

- Specify the optimum recipe for each product with minimum cost.

- Maximize throughput with minimum cost.
- Specify analysis report for uncertain parameters.

- Minimize lead time.

- Maximize utilization of the equipments and storage tanks.

- Minimize operational cost.

- Proposed a schedule for the production plan.

\subsection{Production Planning And}

\section{Scheduling In Oil Refineries}

$\mathrm{P}_{\text {roduction planning is the }}$ discipline related to the high level decision-making of macro level problems for allocation of production capacity. The primary objective of planning is to determine a feasible operating plan consisting of production goals that optimizes a suitable economic criterion, maximizing total profit (or equivalently, of minimizing total costs), over a specific extended period of time in the future, typically in the order of few months to few years; giving marketing forecasts of 
prices and market demands for products [9, 10 and 11]. Planning problems can mainly be distinguished as strategic, tactical or operational, based on the decisions involved and the time horizon considered. The strategic level planning considers a time span of more than one year and covers a whole width of an organization. At this level, approximate and/or aggregate models are adequate and are mainly considered as future investment decisions. Tactical level planning typically involves a midterm horizon of few months to a year where the decisions usually include production, inventory and distribution. Operational level covers shorter periods of time spanning from one week to three months where the decisions involve actual production and allocation of resources. For a general process operations hierarchy, planning is the highest level of command. As shown in Figure (1), enterprise wide planning provides production targets for each individual site where each site transforms the plans into schedules and operational/control targets [12 and13].

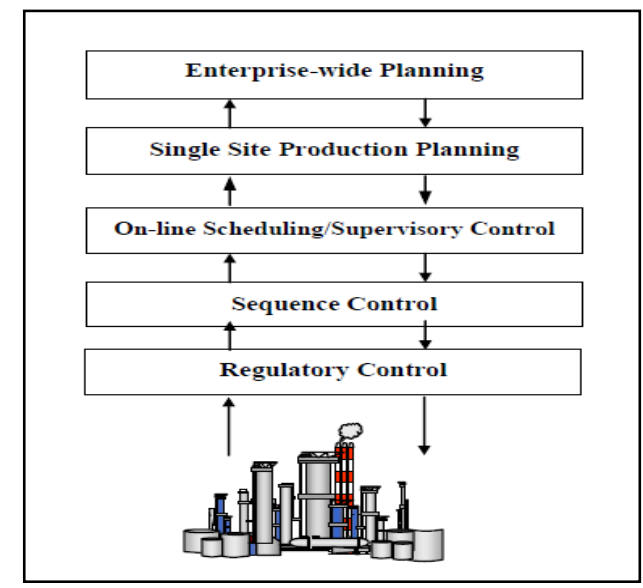

Fig. (1) Process Operations Hierarchy.

Production scheduling deals with lower level decision-making of micro-level problems embedded in the production planning problem 
that involves deciding on the methodology that determines the feasible sequence or order and timing in which various products are to be produced in each piece of equipment, so as to meet the production goals that are laid out by the planning model. The major objective of scheduling is to efficiently utilize the available equipment among multiple types of products to be manufactured, to an extent necessary to satisfy production goals. Therefore, optimizing is a suitable economic or systems performance criterion; over a short time horizon ranging typically from several shifts to several weeks. Scheduling models, are concerned more with the feasibility of operations to accomplish a given number and order of tasks [8].

The schedule is revised as needed so that it always starts from what is actually happening with revisions that typically occur on each day or on each shift. Scheduling can be viewed as a reality check on the planning process [15]. The main aim of scheduling is the implementation of the plan, subjected to the variability that occurs in the real world. This variability could be present in the form of feedstock supplies and quality, the production process, customer requirements, or transportation. Schedulers assess how production upsets and other changes will force deviations from the plan.

\subsection{The Gasoline Blending Process \\ The gasoline is one of the} most important refinery products because it can yield (60 - 70) \% of a typical refinery's total revenue [11, 16 and 17]. Gasoline blending is the final step of processing gasoline products. The gasoline blending operation often determines the operating conditions of the upstream units. Due to the importance of the gasoline blending, a gasoline blending process is included in the proposed approach. Gasoline blending is the process of blending several gasoline blending stocks that 
are produced in upstream units or purchased from the market to make several grades of gasoline according to the specifications. The objective of the planning and scheduling for gasoline blending is to allocate the available gasoline blending components in such a way as to meet product demands and specifications at the least cost and to produce products which maximize the overall profit. Different gasoline blending stocks have different properties. Different grades of gasoline also have different specifications. The core of a gasoline blending model is the prediction of gasoline properties from the properties of the blending stocks. Some refineries can have up to 30 different gasoline blending feed stocks [14].

The main blending feed stocks used are:

1. Light Straight Run Naphtha or LSR, which is the gasoline boiling range cut from the atmospheric distillation tower.
2. Ismorate the gasoline cut from isomerization unit.

3. CCR feedstock the gasoline cut from Continues Catalytic Regeneration.

4. Reformate1 the gasoline from the catalytic reforming unit.

5. Reformate2(or power former) from power former unit

6. Catalytic Cracking gasoline (the gasoline cut from the Fluidized Catalytic Cracking Unit

7. Alkylate, the gasoline cut from the liquid catalyzed alkylation unit.

8. n-Butane, normal butane from various processing units.

9. 'Hydrocrackate', the gasoline fraction from the hydrocracker.

10.Additives like Tetra Ethyl Lead (TEL), Ethanol and Methanol.

The first nine blending stocks are produced and blended in the refinery while the additives (TEL, ethanol and methanol) are purchased [14 and19]. Therefore, adjusting the operating conditions of upstream units according to the gasoline blending is essential to 
make the refinery operation profitable. Gasoline is typically retailed in grades of regular, premium and supper, which are differentiated by the posted octane number. The octane number $(\mathrm{ON})$ and Reid Vapor Pressure (RVP) is the most common required specifications.

\section{Developing Short Term} Planning And Scheduling For

\section{Gasoline Blending}

In the present work integrating short-term planning and scheduling model for product blending is proposed, by using mathematical model and sensitivity analysis for predication uncertain parameters.

\subsection{Proposed Approach}

The proposed approach is shown in Figure (2). It consists of two mathematical models with two levels. The first level deals with the production planning formulated as Linear Programming (LP) or Linear Goal Programming (LGP) if there are multi objectives to solve the optimum quantity decision of products that meet product specifications with minimum cost. Then the analyzed results are incorporated as a fixed decision into scheduling model (the second level).The results of the first level are considered as production guidelines and utilized as input to the second level to reduce the number of variables and computational results in the scheduling model. In scheduling level the main objective is to implement the production plan with minimum cost according to due date and available equipments and resources. 


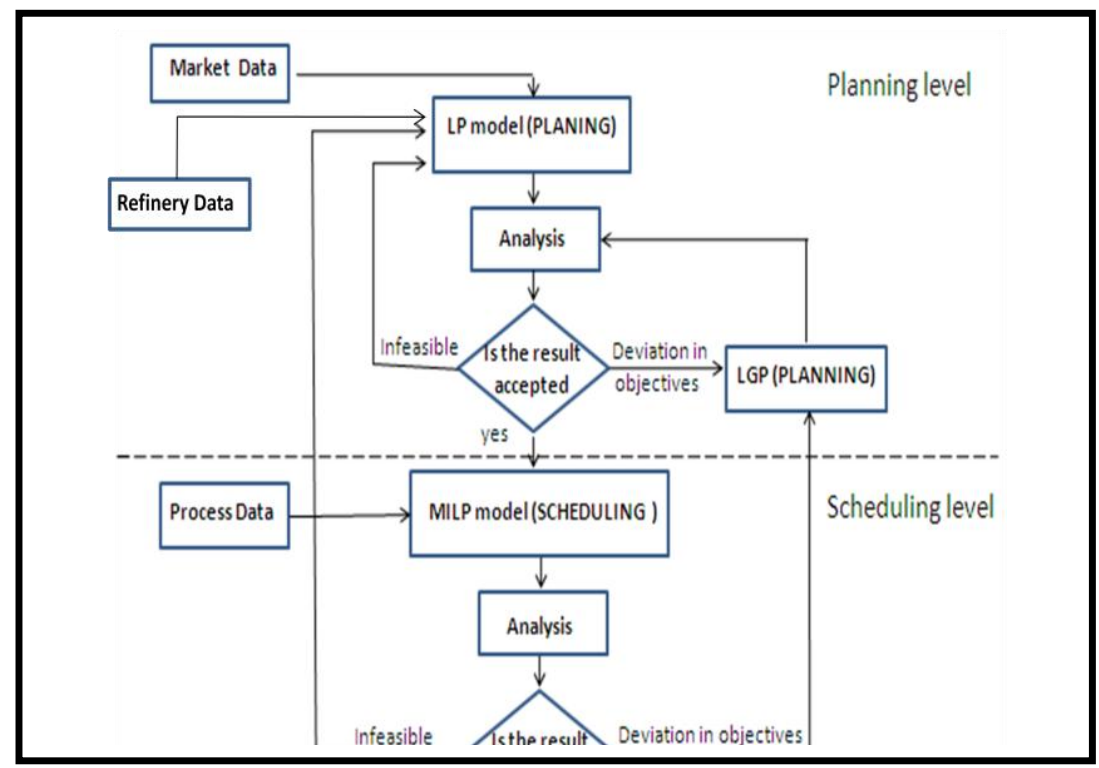

Fig. (2) Proposed Approach structure

The main features of the proposed approach shown in figure (2) can be summarized as follows:

1. The proposed approach consists of two levels. The first is the planning level in which LP model is proposed to solve production quality and quantity issues. Then MILP model is utilized to solve production scheduling issue.

2. The goals deviations are tested by sensitivity analysis for uncertain variables such as demand, component quantity and profit contribution for each component.
3. The use of binary and integer variables to represent assignment decisions,

4. The use of discrete time representations method. The term "time slot" is used to represent a time interval with known duration and for discrete time.

5. Variable product recipes are considered and product properties are predicted by linear constraints.

6. Equivalent blenders are worked in parallel for different product grades.

Deviation from the planning level may be generated in the scheduling level, and sometimes even feasible solution in the planning level may 
be difficult to apply in the scheduling level. The deviation from the planning objectives occurs because of the following reasons.

1. The effects of change over and daily inventories are neglected.

2. The uncertainty in demand or available components specifications.

3. The quality and quantity giveaway of the intermediate products during the scheduling horizon because of the fluctuation in the production units.

4. In the planning level the product demands are defined for a period of time and not for precise delivery dates.

5. Simultaneous allocation of equipment cannot be included within planning level.

As shown in figure (2) the results are to be analyzed employing sensitivity analysis. The appropriate strategy will be according to the results of the sensitivity analysis that will be as follow:

1. Optimal solution that will be accepted.
2. The deviation in goals will be resolved by linear goal programming.

3. Infeasible schedule that will be feedback to the planning level to be processed.

For the proposed approach it is assumed that the following are given:-

(1). Operational planning horizon 7 days.

(2).Scheduling horizon, 2 days.

(3). A set of component product tanks with minimum and maximum capacity restrictions.

(4). A set of blend headers working in parallel that can be allocated to each final product.

(5). Initial stocks for components.

(6). Component supplies with known flow rates from production unit.

(7). Product lifting with constant flow rates. 
(8). Discrete time representation is used and the starting time of the scheduling horizon is (8 AM)

The objectives of planning level are to determine:

- The total volume of each final product.

- The optimum recipes for each product that minimize cost.

- Maximize throughput with minimum cost.

- Specify analysis report for uncertain parameters.

While the objectives of scheduling level are to determine:

- The optimal timing decisions for production and storage tasks.

- The optimum pumping rates for components and products.

- The assignment of blenders to final products.

- The inventory levels of components and products in storage tanks.
In order to describes the problem variables, Fig. (3), Illustrates gasoline blending, which is treated as two; logistic and quality problems. Where the logistic defines the way in which the products are processed with respect to time and available equipments and the quality constraint will explain how the available components will be blended or mixed together to produce on specification products with minimum cost. The key decision variables involved in this problem are the following; The continuous variable $x i j$ defines the volumetric quantity of component $j$ that must be transferred to produce product $\mathrm{i}$ during the time slot $t$ .While $y i$ denotes the volumetric quantity of product $i$ that may be blended during each time slot $t$. The solution of the scheduling problem defines the way in which the products are processed with respect to time and available equipments. The continuous variables $V J j$, define the amount of components $j$ 
being stored at each time point $t$, and $V I i, t$ define the amount of product $\mathrm{i}$ being stored at each time point $t$, Finally, the discrete variable
$A i, t$ defines which products are allocated to blenders in each time slot $t$.

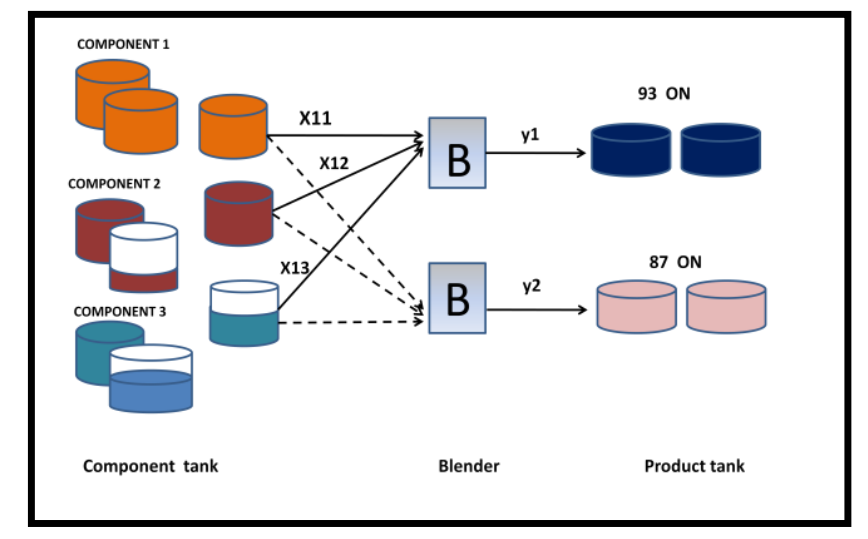

Fig. (3) off-line blending

The mathematical formulation of discrete time is presented (the time interval divided into equal intervals 1 day) assuming a common time grid for all resources working in parallel. Therefore the use of a discrete time representation will be proposed in this work. Some refineries can have up to 30 different gasoline blending feed stocks [17].The proposed mathematical models are presented using the following nomenclature:

\subsection{Problem Formulation}

In this approach there are two levels employed with two mathematical models. 


\subsubsection{The Planning Level (Linear Programming)}

The first level is the operation planning level. In which the planning horizon is fixed to one week. The problem is formulated as LP or if the refinery wanted to verify multi objectives the model will be formulated as LGP. The goal of planning level is to determine the optimum quantity decisions. The main objective in this level is to maximize net profit subject to meet quality and quantity requirements. The constraints of this level are formulated as follow.

\subsubsection{Product Demand Constraint.}

Product demand in oil refinery is provided by blending several available components; therefore, constraint (1) guarantees that an amount of blended product yit will be equal to or less than the required demand ddit.

$\sum_{\mathrm{i}}^{\mathrm{I}} \mathrm{yiH} \leq \mathrm{ddiH}$

\subsubsection{Component Availability Constraint.}

\section{This constraint impose that the used component xijt must be less than} or equal to the available amount of components $\mathrm{AV}$ jt as described in constraint (2).

$$
\sum_{\mathrm{i}}^{\mathrm{I}}\left(\sum_{\mathrm{j}}^{\mathrm{J}} \mathrm{xijH} \leq \mathrm{AVjH}\right)
$$




\subsubsection{Product Quality Constraint.}

Every final product specifications reflect the specifications of its blended components. In this model, Octane Number (ON) and Reid Vapor Pressure (RVP) are used as the quality index of gasoline and viscosity for fuel oil; therefore the constraint (3) will satisfy ON requirements and (4) satisfy RVP requirements.

$\sum_{i}^{I}\left(\left(\sum_{j}^{J}\right.\right.$ qj $\left.\left.x i j\right)-\left(\sum_{j}^{J} x i j ~ Q i\right) \geq 0\right)$

$\sum_{i}^{I}\left(\left(\sum_{j}^{J}\right.\right.$ qj xij $\left.)-\left(\sum_{j}^{J} x i j Q i\right) \leq 0\right)$

\subsubsection{Product Composition Constraints}

\section{The final product yit will be equal to the summation of its blended} components xijt as expressed below.

$\sum_{i}^{I} \sum_{j}^{J} x i j H=y i H$

\subsubsection{Surplus Constraint}

$\mathrm{D}_{\mathrm{ue}}$ to the surplus components the penalty constraint may be add to the objective function and the constraint (6) determines the surplus component $\mathrm{Sj}$ that is equal to the available component $\mathrm{AVjH}$ volume - the required volume of the same component xijt . 
$\mathrm{SH}=\sum_{\mathrm{j}}^{\mathrm{J}} \mathrm{AVjH}-\mathrm{xijH} \quad$ for $\mathrm{j}=1$ to $\mathrm{J}$

Where surplus component $\mathrm{Sj}$ is equal to the available component $\mathrm{AVjH}$ minus the required component xijt for mixing of the required product $\mathrm{i}$. Constraint

\subsubsection{Production Rule Constraints}

These constraints include the conditions that describe refinery limitations like production unit status, inventory situation and managerial requirements for example if the refinery wanted to contracts to produce specific quantity for specific product therefore the constraint (1) will be modified to constraint (7)

$\sum_{\mathrm{i}}^{\mathrm{I}} \mathrm{ddciH} \leq \mathrm{yiH} \leq \mathrm{ddiH}$

\subsubsection{Objective Function.}

While satisfying all above constraints, the main objective of the blending problem is to maximize net profit by maximize contribution profit for each component pfij X $i j$ - penalty cost $\mathrm{pj}$ ) according to availability of resources the quality and quantity requirement.

$\operatorname{Max} \sum_{\mathrm{i}}^{\mathrm{I}} \sum_{\mathrm{j}}^{\mathrm{J}}$ pfij XijH $-\sum_{\mathrm{j}}^{\mathrm{J}}$ paltys $\mathrm{SjH}$ 
Financial risk analysis of the results is employed utilizing Quantitative System for Business under windows (WINQSB) software. The output of this level will be regarded as production guidelines and utilize as input for the next level (scheduling level) as shown in figure (3.1).

\subsubsection{The Planning Level (Linear Goal Programing)}

\section{The company may be has multi objectives, therefore, linear goal} programming will be use and formulated according to priorities of these goals (Ranked Goals) to maximize or minimize deviation variables in goal constraints. Therefore, some constraints must be modifying to be goal constraints like (1a) and (8a) and the others stay as it formulated.

$\sum_{\mathrm{i}}^{\mathrm{I}} \mathrm{yiH}+\mathrm{MADgh}-\mathrm{MIDgh}=\mathrm{ddH}$

The constraint (2) states there are multi objectives in LGP model where the MADi, MIDi represents variable deviations.

$\underset{i}{I}$ price yih $-\sum_{i}^{I} \sum_{j}^{J}$ prf xijh- $-\sum_{j}^{J}$ palty $S j h+M A D g h-M I D g h=0$

The objective function will minimize the deviation variables according to planning goals. 


\subsubsection{The scheduling level}

In this level the output of the planning model will be utilized as input to the scheduling model. Applying an MILP model, discrete time representation that assumes that the entire scheduling horizon is divided into a finite number of consecutive time slots (each interval equal 1day). The beginning time of each time slot of the scheduling horizon is $(8 \mathrm{AM})$ with two days time horizon. The constraints of this level formulated as follow

\subsubsection{Material Balance Equation For Components}

\section{The amount of component $j$ in tank $z$ at event point $t+1(V J j z t+1)$ is} equal to that at event point $t$ (inijzt) adjusted by any amounts transferred from production unit Fjet and/or delivered to the blender at event point $t\left(\sum x i j t\right)$. This relation is expressed by constraint (8). Constraint (9) imposes that the target flow Fljzt should be between the upper and lower bounds of the flow rates of component $j$ transferred from tank $z$ to the blender.

$V J j z t+1=\mathrm{ini} j z t+$ Fetjt $t-\sum_{\mathrm{j}}^{\mathrm{J}} x i j t$

Fl min $j z t$ Ait $\leq$ Fljzt $\leq$ Flmax jzt Ait

The constraint (10) imposes the target flow for component $j$ to be equal to the minimum flow rate plus slack variable multiplied by component percentage .

$\mathrm{Fl} j z t-\mathrm{Fl} \min j z t-\mathrm{CP} j i t \mathrm{SLjz} z t \geq 0$ 


\subsubsection{Volumetric Component Concentration Constraints}

Constraint (11) is to ensure that volumetric component concentration that maintains the solution feasible to produce the demand at the satisfied quality and quantity.

$x i j t \leq \operatorname{con} j i t$

\subsubsection{Component Storage Capacity}

Constraint (12) imposes a volume capacity limitation of component $\mathrm{j}$ in component tank $\mathrm{z}$ at event point $t$.

$V \min j z t \leq V J j z t \leq V \max j z t$

\subsubsection{Product Composition Constraint}

Constraint (13) imposes that the blended product i will be equal or less than the summation of its blended components $\mathrm{j}$ at time slot $\mathrm{t}$.

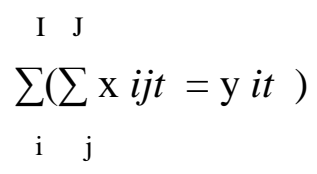




\subsubsection{Product Constraints}

Constraint (14) impose the blended product will be equal to or more than satisfied demand for product $i$ in time $t$ and equal or less than maximum capacity of product tank.

$\sum_{\mathrm{t}}^{\mathrm{T}} \sum_{\mathrm{i}}^{\mathrm{I}} \mathrm{Sd} i t \leq \mathrm{y} i s t \leq \mathrm{MCist}$

\section{$\underline{\text { 3.3.3.6 Assignment constraint }}$}

Constraint (15) impose that the summation of binary variable Ait should be equal to or less than the maximum number of blender $\mathrm{N} t$ that can be working in parallel during time slot $t$ :

$$
\sum_{\mathrm{i}}^{\mathrm{I}} \boldsymbol{A} i t \leq N t
$$

Constraint (16) imposed the blended product yit will be equal to or less than the result of multiplying binary variable kit by satisfied demand $\mathrm{Sd} d t$ to due date.

$\sum_{\mathrm{i}}^{\mathrm{I}} \mathrm{y} i t \leq \mathrm{Sd} d t(\mathrm{kit})$

Constraint (17) imposed the blended product yit will be equal to or less than the result of multiplying binary variable kit by satisfied demand $\operatorname{Sd} d t$ to due date. 
$\sum_{\mathrm{i}}^{\mathrm{I}} \mathrm{y} i t \leq \mathrm{Sd} d t(\mathrm{~A} i t)$

\subsubsection{Material Balance Equation For Products Tanks}

Constraints (18) \& (19) express that the volumetric amount of product $i$ in tank $s$ at event point $t+1$ is equal to that at event point $t$ adjusted by any amounts transferred from the blender - the lifted amount at event point $t$.

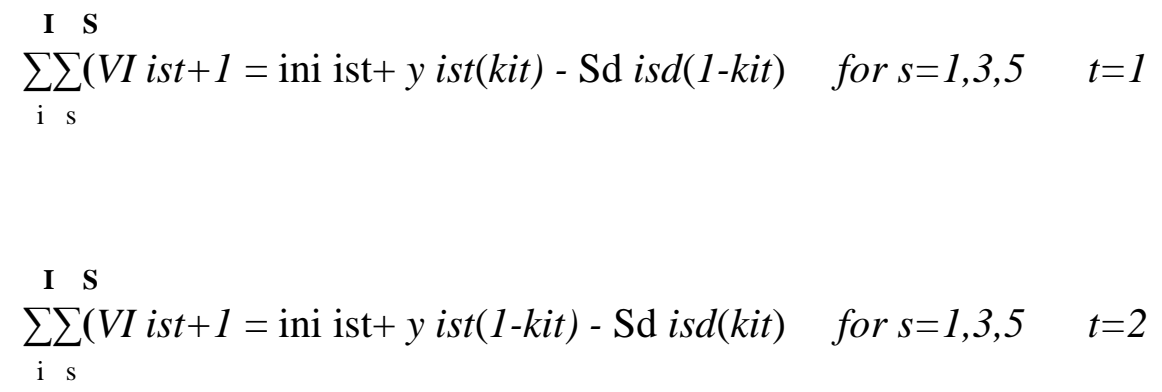

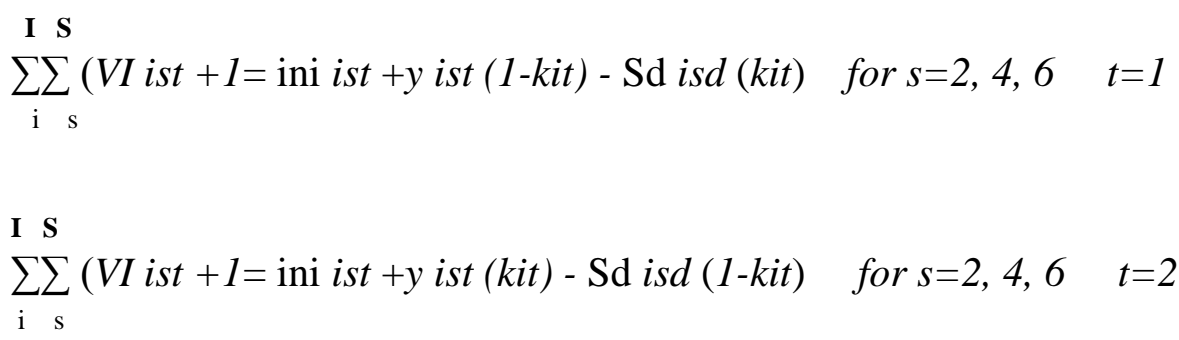

\subsubsection{Product Storage Capacity}

Constraint (20) imposes a volume capacity limitation of product $i$ in product tank at event point $t$. Constraint (21) imposes the target flow Flist 
should be between the upper and lower bounds of the flow rates of product transferred from tank $s$ to the customer.

$V \min i s t \leq V I$ ist $\leq V \max$ ist

Fll min $i z t$ kit $\leq$ Fllizt $\leq$ Fllmax izt kit

The constraint (22) imposes the target flow for product $i$ that is equal to the minimum flow rate plus slack variable.

Fllist - Fll min ist - SLList $\geq 0$

An additional set of variables and equations is required to define penalties that can be added to the objective function of the proposed model. These penalties can partially relax some hard problem specifications that can generate infeasible solution when real world problems are addressed.

Constraint (23) will satisfy quality requirements.

$\sum_{i}^{I} \underset{j}{(J} q$ qj xij $\left.)-\left(\sum_{j}^{J} x i j Q i\right) \geq 0\right)$

\subsubsection{Penalty For Intermediate Product Shortage}

A common source of infeasible solutions is the surplus amount of component required to satisfy either predefined component concentration or certain market specifications. Intermediate products can be purchased or sold at negative cost from a third-party. The continuous variable Si,t defines the 
amount of intermediate product $j$ needed in time slot $t$, to relax minimum inventory constraints:

$V J j z t=\operatorname{inij} z t+$ Fet $j \underset{j}{-\sum_{j}} x i j t+S j t$

The penalty term (25) is directly proportional to the component purchase cost as show below:

$$
\mathrm{p}=\sum_{\mathrm{t}}^{\mathrm{T}} \underset{\mathrm{i}}{\mathrm{I}}(\text { pltys } j \text { Sit })
$$

\subsubsection{Penalty For Demand Deviation}

\section{$\mathrm{D}_{\mathrm{ue}}$ to the uncertainty demand, penalty may be added to the production} cost and the constraints (26) \& (27). The required demand will be equal to or less than the amount of blended product plus initial product in storage tank plus the amount of product purchased from a third party to satisfy the demand.

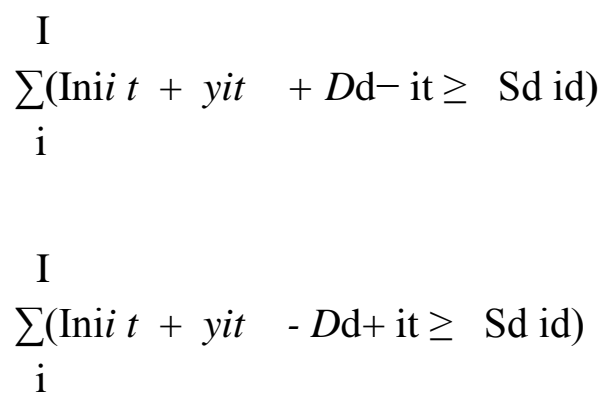

The constraint (28) imposes the generated penalty of demand.

$$
\mathrm{p}=\sum_{\mathrm{i}}^{\mathrm{I}} \mathrm{pltyd} i t D \mathrm{~d}-\mathrm{it}+\sum_{\mathrm{i}}^{\mathrm{I}} \text { pltydit } D \mathrm{~d}+\mathrm{it}
$$




\subsubsection{Objective Function}

$W_{\text {hile satisfying all quality and logistic issues, the main objective of }}$ the scheduling model is to maximize the net profit. Constraint (29) is to maximize the result of the summation of contribution profit for each component used to satisfy the required demand minus the summation of penalty:

$$
\begin{aligned}
& \text { T I J P } \\
& \text { Max } \sum \sum \sum \text { pfij Xijt }-\sum \mathrm{p}+\mathrm{SLjt}+\text { SLLit } \\
& \mathrm{t} i \mathrm{j} \quad \mathrm{p}
\end{aligned}
$$

The proposed model will be employed and tested for three different case studies employing the available resources at AL-Dura Refinery.

\section{Case Study}

In the near future a series of development processes in AL-Dura refinery, two conversion units will be constructed. Therefore, the refinery may produce three grades of gasoline regular, premium and supper (y1, y2 and y3) with different octane numbers $(87,89$ and 93) for the demand of (280000, 105000 and 77000). The tables below show the required data. By the proposed approach, it is possible to define optimum operation plan and then schedule the results, if the refinery is committed is to satisfy $7000 \mathrm{bpd}$ of product y1 and 170000 bpd of product y3 according to customers demand. Figure (4) shows the systematic representation for this case study. 


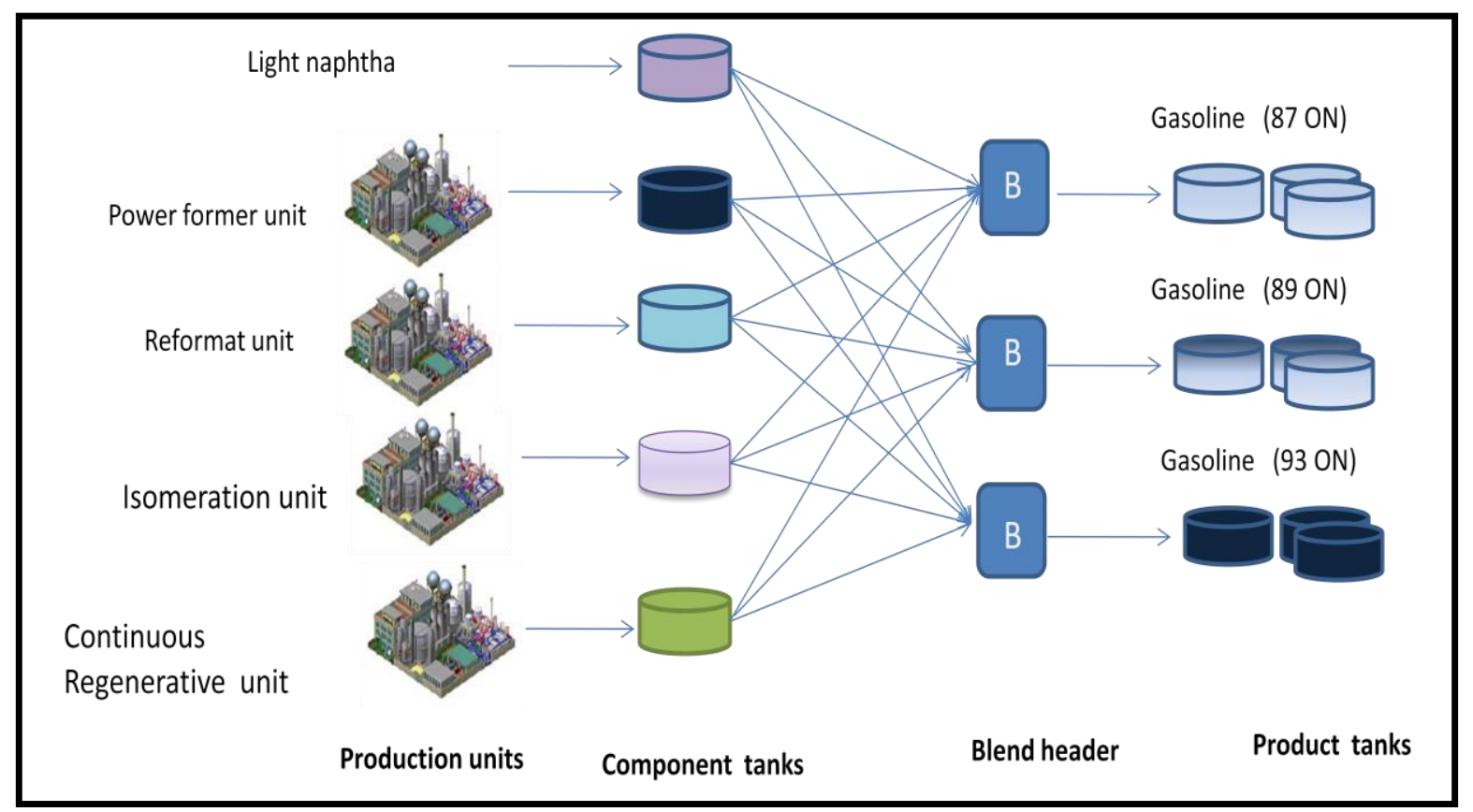

Fig. (4) show program solution window

Table (1) Intermediate product data

\begin{tabular}{|c|c|c|c|c|c|c|}
\hline Seq. & Material & Symbol & $\begin{array}{c}\text { Quantity } \\
\text { Barrel }\end{array}$ & ON & $\begin{array}{c}\text { RVP } \\
\text { PSI }\end{array}$ & $\begin{array}{c}\text { Cost } \\
\text { ID }\end{array}$ \\
\hline 1 & Light & X1 & 12000 & 66 & 11 & 10140 \\
\hline 2 & naphtha & & & & & \\
\hline & $\begin{array}{c}\text { Power } \\
\text { former }\end{array}$ & X2 & 10000 & 80 & 8 & 11700 \\
\hline 3 & Ismorate & X3 & 10000 & 88 & 17 & 12948 \\
\hline 4 & Reformat & X4 & 5000 & 90 & 10 & 13416 \\
\hline 5 & CCR & X5 & 15000 & 99 & 5 & 14820 \\
\hline
\end{tabular}


Table (2) data for the required product (daily demand)

\begin{tabular}{|c|c|c|c|c|c|}
\hline product & ON & $\begin{array}{c}\text { RVP } \\
\text { psi. }\end{array}$ & $\begin{array}{c}\text { Daily } \\
\text { Demand } \\
\text { barrel }\end{array}$ & $\begin{array}{c}\text { Price } \\
\text { B.ID }\end{array}$ & Due date \\
\hline Y1 & 87 & 13 & 40000 & 16380 & 8 am \\
\hline Y2 & 89 & 11 & 15000 & 16848 & 2 pm \\
\hline Y3 & 93 & 11 & 11000 & 17472 & 11 am \\
\hline
\end{tabular}

Table (3) intermediate tank data

\begin{tabular}{|c|c|c|c|c|c|c|}
\hline $\begin{array}{l}\text { Tank } \\
\text { number }\end{array}$ & Material & $\begin{array}{l}\text { Capacity } \\
\text { B. }\end{array}$ & $\begin{array}{l}\text { Min } \\
\text { volume } \\
\text { B. }\end{array}$ & $\begin{array}{l}\text { Max } \\
\text { volume } \\
\text { B. }\end{array}$ & $\begin{array}{l}\text { Min } \\
\text { flow } \\
\text { B.hr }\end{array}$ & $\begin{array}{l}\text { Max } \\
\text { flow } \\
\text { B/hr }\end{array}$ \\
\hline TK 1 & $\begin{array}{l}\text { Light } \\
\text { naphtha }\end{array}$ & 73000 & 10000 & 73000 & 100 & 1200 \\
\hline TK 2 & $\begin{array}{l}\text { Power } \\
\text { former }\end{array}$ & 73000 & 10000 & 73000 & 100 & 1200 \\
\hline TK 3 & Ismorate & 73000 & 10000 & 73000 & 100 & 1200 \\
\hline TK4 & Reformat & 73000 & 10000 & 73000 & 100 & 1200 \\
\hline TK5 & CCR & 73000 & 10000 & 73000 & 100 & 1200 \\
\hline
\end{tabular}

Table (4) Product tank data

\begin{tabular}{|l|l|l|l|l|l|l|}
\hline $\begin{array}{l}\text { Tank } \\
\text { number }\end{array}$ & Material & capacity & $\begin{array}{l}\text { Min } \\
\text { volume }\end{array}$ & $\begin{array}{l}\text { Max } \\
\text { volume }\end{array}$ & $\begin{array}{l}\text { Min } \\
\text { flow }\end{array}$ & $\begin{array}{c}\text { Max } \\
\text { flow }\end{array}$ \\
\hline TK6 & REGULAR & 73000 & 10000 & 73000 & 250 & 2000 \\
\hline TK7 & REGULAR & 73000 & 10000 & 73000 & 250 & 2000 \\
\hline TK8 & PREMIUM & 73000 & 10000 & $\mathbf{7 3 0 0 0}$ & $\mathbf{2 5 0}$ & $\mathbf{2 0 0 0}$ \\
\hline TK9 & PREMIUM & $\mathbf{7 3 0 0 0}$ & $\mathbf{1 0 0 0 0}$ & $\mathbf{7 3 0 0 0}$ & $\mathbf{2 5 0}$ & $\mathbf{2 0 0 0}$ \\
\hline TK10 & SUPPER & $\mathbf{7 3 0 0 0}$ & $\mathbf{1 0 0 0 0}$ & $\mathbf{7 3 0 0 0}$ & $\mathbf{2 5 0}$ & $\mathbf{2 0 0 0}$ \\
\hline TK11 & SUPPER & $\mathbf{7 3 0 0 0}$ & $\mathbf{1 0 0 0 0}$ & $\mathbf{7 3 0 0 0}$ & $\mathbf{2 5 0}$ & $\mathbf{2 0 0 0}$ \\
\hline
\end{tabular}




\subsection{The Planning Model}

The developed model

employs (LP) at the planning level \& employs (WIN QSP system version 1.00) run on widow $X P$, As shows in figure (5) The results generated at this level are shows in table (5) and Figure (6).

Table (5) shows the expected profit, which comes from selling $280,000 \mathrm{bbl}$ of regular gasoline, $32,869 \mathrm{bbl}$ of premium gasoline and $7000 \mathrm{bbl}$ of supper gasoline weakly. Therefore, the refinery throughput will be 45695 bpd of three grades of gasoline product according to due date, the residue of intermediate product (naphtha) reach to 6,304 bpd. Therefore, in order to reduce the surplus naphtha, the refinery has two choices, either to use additives to produce high grade gasoline, or minimize naphtha production to 6,304 bpd.

The solution is optimum, when unit profit of light naphtha product ranges from
$(6,240$ to 12688 ID) Also If unit profit of reformat ismorat ranges from $(3,138$ to 3,432 ID) And if unit profit of reformat ranges from $(2,964$ ID 0 maximum positive value) Figure (7) shows the optimum recipe for each product.

The net profit will be sensitive by 2,523 ID to any decrease or increase of one barrel of power former since its quantity stay between 16,000 to $142,500 \mathrm{bbl}$, and sense 3,608 ID also in any decrease or increase of one barrel of ismorat since its quantity stay between 35,636 to $116,136 \mathrm{bbl}$. Also sense 3,723 ID by any decrease or increase by one barrel of reformat since its quantity stay between 3500 to $77,291 \mathrm{bbl}$, and sense 4,944 ID also in any decreasing or increasing by one barrel of power former since its quantity stay between 82,090 to 135,757 bbl. 


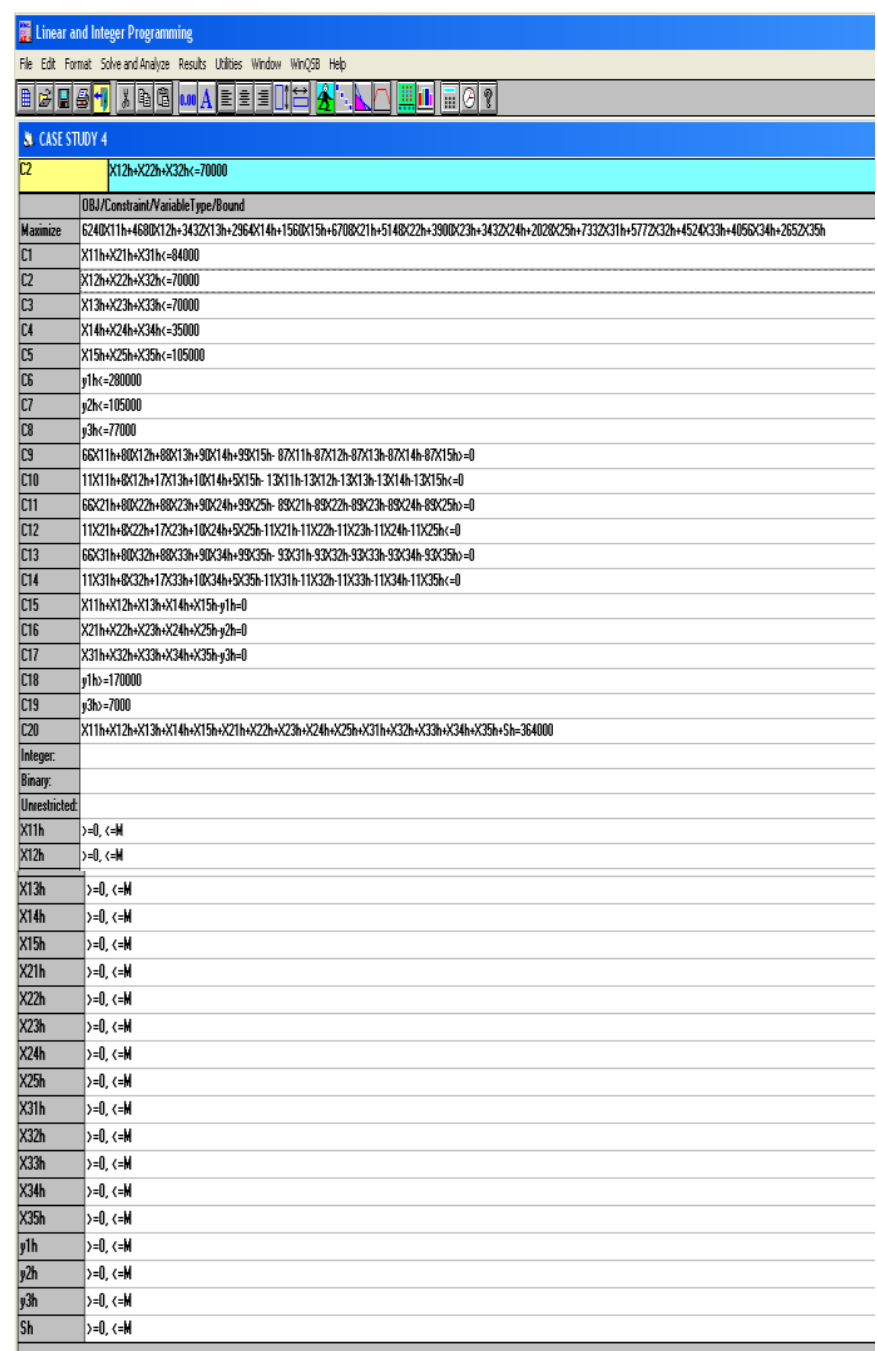

Fig.(5) WIN QSB input window for case study 3 


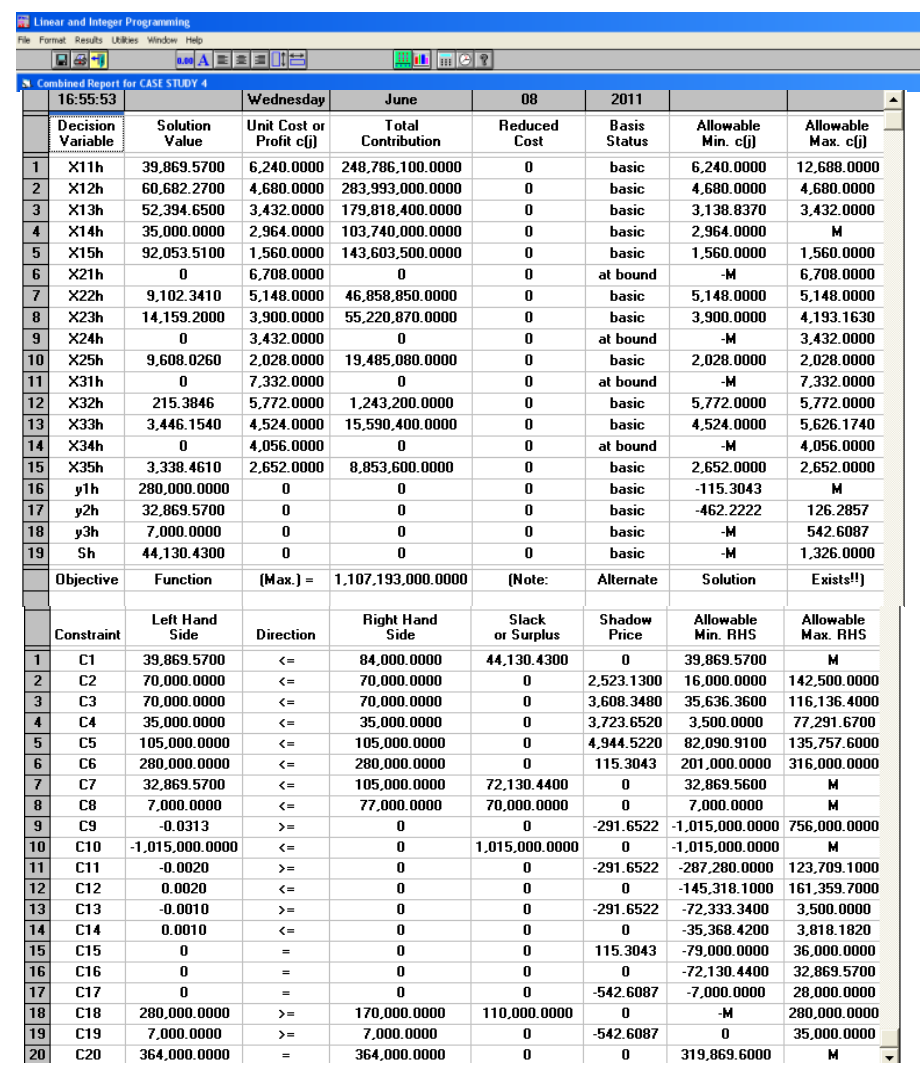

Fig. (6) show program solution window

Table (5) summary solution for case study (4)

\begin{tabular}{|c|c|c|c|}
\hline Products & Quantity & $\begin{array}{c}\text { Profit for } \\
\text { each } \\
\text { barrel ID. }\end{array}$ & $\begin{array}{c}\text { Contribution } \\
\text { profit ID. }\end{array}$ \\
\hline $\begin{array}{c}\text { Regular } \\
\text { gasoline }\end{array}$ & $\mathbf{2 8 0 0 0 0}$ & $\mathbf{3 , 4 2 8}$ & $\mathbf{9 6 3 , 9 4 2 , 8 0 0}$ \\
\hline $\begin{array}{c}\text { Premium } \\
\text { gasoline }\end{array}$ & $\mathbf{3 2 , 8 6 9}$ & $\mathbf{3 , 4 1 2}$ & $\mathbf{1 1 7 , 5 6 3 , 0 8 0}$ \\
\hline $\begin{array}{c}\text { Supper } \\
\text { gasoline }\end{array}$ & $\mathbf{7 0 0 0}$ & $\mathbf{3 , 6 6 9}$ & $\mathbf{2 5 , 6 8 7 , 2 0 0}$ \\
\hline Surplus & $\mathbf{4 4 , 1 3 0}$ & $\mathbf{- 6 2 4 0}$ & \\
\hline & $\begin{array}{c}\text { Objective } \\
\text { function }\end{array}$ & & $\mathbf{1 , 1 0 7 , 1 9 3 , 0 0 0}$ \\
\hline
\end{tabular}




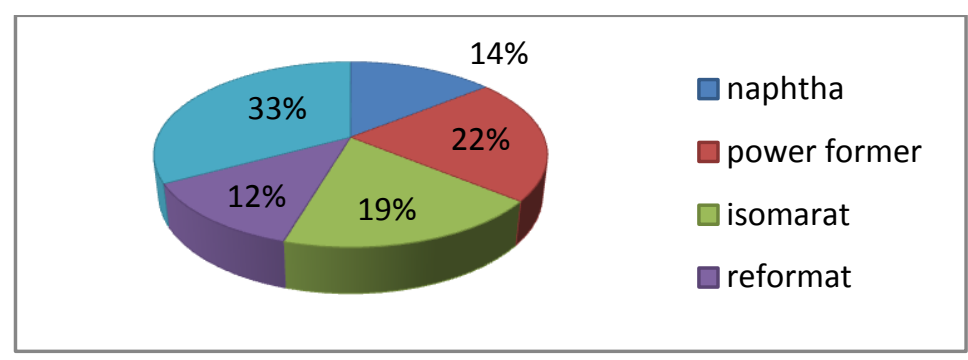

a) Components percentage of regular gasoline

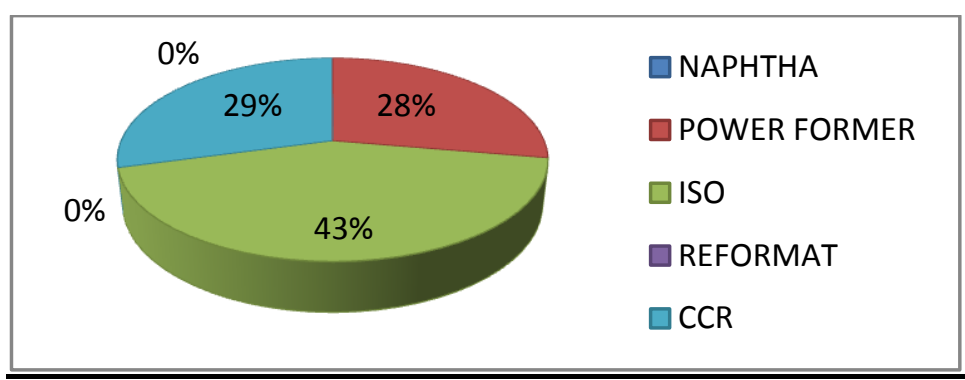

b) Components percentage of premium gasoline

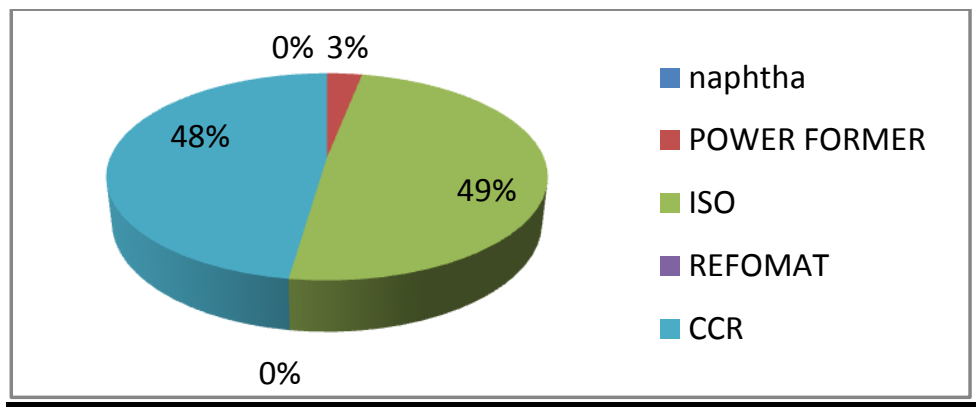

c) Components percentage of supper gasoline

Fig. (7) optimum recipes for different gasoline grades
a) Regular gasoline
b) premium gasoline
c) supper gasoline

\subsection{Scheduling Model}

The results of the planning

level shown in the previous tables describe the optimum quantity decisions for different products ( regular, premium and supper) and determine the optimum component concentrations for each product, that minimize product recipes cost and meet product specifications. These results will be used as input to the scheduling level. The main objective 
of the second level is to minimize inventory holding and operational cost subject to product due date, that occur by release of an optimum time table for each part of blending system. The optimum timing decisions maximize the utilization of product and component tanks that take into consideration the due date of product. Appendix A shows scheduling results. The Gantt chart of figure (8) shows the summary of intermediate product flow rates for three products for two days schedule. Figure (9) shows a summary of product tanks for three products of two days schedule. The next tables shows more details of flow rate for intermediate product tanks for different gasoline grades for two days scheduling horizon.

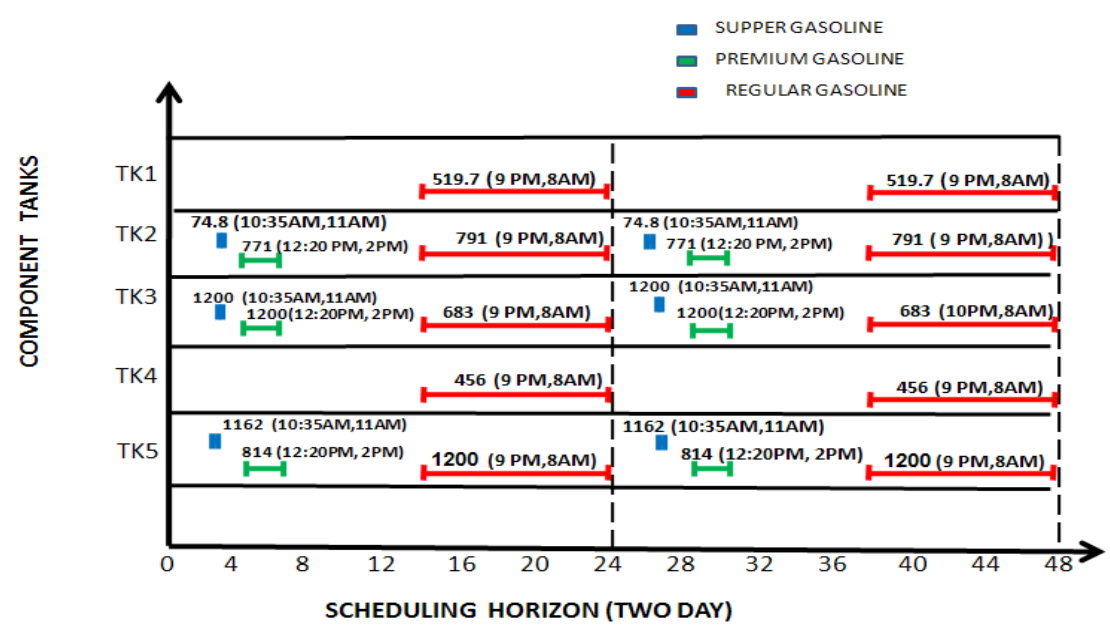

Fig. (8) Gantt chart showing two days scheduling for intermediate tanks flow rate 
Table (6) Summary of intermediate tanks schedule for regular gasoline

\begin{tabular}{|c|c|c|c|c|c|c|c|}
\hline $\begin{array}{l}\text { Tan } \\
k \text { n. }\end{array}$ & $\begin{array}{c}\text { Compone } \\
\text { nt }\end{array}$ & $\begin{array}{c}\text { Start } \\
\text { period } \\
\text { invento } \\
\text { ry }\end{array}$ & $\begin{array}{c}\text { Flo } \\
\text { w } \\
\text { seq. }\end{array}$ & $\begin{array}{c}\text { Flo } \\
\text { w } \\
\text { B.h } \\
\text { r }\end{array}$ & $\begin{array}{c}\text { Starti } \\
\text { ng } \\
\text { time }\end{array}$ & $\begin{array}{c}\text { Endin } \\
\mathrm{g} \\
\text { time }\end{array}$ & $\begin{array}{c}\text { End } \\
\text { period } \\
\text { invento } \\
\text { ry }\end{array}$ \\
\hline $\begin{array}{c}\text { TK } \\
1\end{array}$ & $\begin{array}{c}\text { Light } \\
\text { naphtha }\end{array}$ & 10000 & $\begin{array}{c}\text { Fl } \\
111\end{array}$ & $\begin{array}{c}519 . \\
7\end{array}$ & 9pm & 8am & 16304 \\
\hline $\begin{array}{c}\text { TK } \\
2\end{array}$ & $\begin{array}{l}\text { Power } \\
\text { former }\end{array}$ & 10000 & $\begin{array}{c}\text { Fl } \\
121\end{array}$ & 791 & 9pm & 8am & 10000 \\
\hline $\begin{array}{c}\text { TK } \\
3\end{array}$ & Isomerat & 10000 & $\begin{array}{c}\text { Fl13 } \\
1\end{array}$ & 683 & 9pm & 8am & 10000 \\
\hline $\begin{array}{c}\text { TK } \\
4\end{array}$ & reformat & 10000 & $\begin{array}{c}\text { Fl } \\
141\end{array}$ & $\begin{array}{c}456 . \\
2\end{array}$ & 9pm & 8am & 10000 \\
\hline $\begin{array}{c}\text { TK } \\
5\end{array}$ & CCR & 10000 & $\begin{array}{c}\text { Fl } \\
151\end{array}$ & $\begin{array}{c}120 \\
0\end{array}$ & 9pm & 8am & 10000 \\
\hline
\end{tabular}

As shown in table (6) to produce regular grade of gasoline, its need at least 11 hours to blend the required quantity by blend five components. The flow rat of light naphtha will be 519.7 barrel per hour, for power former the flow rate 791 barrel per hour, for ismorat 683 barrel per hour, for reformat 456.2 barrel per hour and for CCR component will be 1200 barrel per hour.
To produce premium gasoline table (7) shows its need 1:40 hours to blend the required quantity of product and use three components. The flow rat of power former component will be 771 barrel per hour, for ismorat will be 1200 barrel per hour and for CCR component will be 814.2 barrel per hour.

Finally to produce supper gasoline 25 minutes need by use 
three components the flow rate of power former will be 74.8 barrel per hour, for ismorat 1200 barrel per hour and for CCR component will be 1162.6 barrel per hour.

Table (7) Summary of intermediate tanks schedule for premium gasoline

\begin{tabular}{|c|c|c|c|c|c|c|c|}
\hline $\begin{array}{c}\text { Ta } \\
\text { nk } \\
\text { n. }\end{array}$ & $\begin{array}{c}\text { Componen } \\
\mathbf{t}\end{array}$ & $\begin{array}{c}\text { Start } \\
\text { inventor } \\
\mathbf{y}\end{array}$ & $\begin{array}{c}\text { Flo } \\
\text { w } \\
\text { seq. }\end{array}$ & $\begin{array}{c}\text { Flo } \\
\text { w } \\
\text { B. } \\
\text { hr }\end{array}$ & $\begin{array}{l}\text { Start } \\
\text { time }\end{array}$ & $\begin{array}{l}\text { End } \\
\text { time }\end{array}$ & $\begin{array}{c}\text { End } \\
\text { period } \\
\text { inventory }\end{array}$ \\
\hline $\begin{array}{c}\text { TK } \\
1\end{array}$ & $\begin{array}{c}\text { Light } \\
\text { naphtha }\end{array}$ & 10000 & $\begin{array}{c}\text { Fl } \\
211\end{array}$ & $\mathbf{0}$ & $\begin{array}{c}12: 20 p \\
\mathrm{~m}\end{array}$ & $2 \mathrm{pm}$ & 16304 \\
\hline $\begin{array}{c}\text { TK } \\
2\end{array}$ & $\begin{array}{l}\text { Power } \\
\text { former }\end{array}$ & 10000 & $\begin{array}{c}\text { Fl } \\
221\end{array}$ & $\begin{array}{c}77 \\
1\end{array}$ & $\begin{array}{c}12: 20 p \\
\text { m }\end{array}$ & $2 \mathrm{pm}$ & 10000 \\
\hline $\begin{array}{c}\text { TK } \\
3\end{array}$ & Isomerat & 10000 & $\begin{array}{c}\text { F12 } \\
31\end{array}$ & $\begin{array}{l}12 \\
00\end{array}$ & $\begin{array}{c}12: 20 p \\
m\end{array}$ & $2 \mathrm{pm}$ & 10000 \\
\hline $\begin{array}{c}\text { TK } \\
4\end{array}$ & reformat & 10000 & $\begin{array}{c}\text { Fl } \\
241\end{array}$ & $\mathbf{0}$ & $\begin{array}{c}12: 20 p \\
m\end{array}$ & $2 \mathrm{pm}$ & 10000 \\
\hline $\begin{array}{c}\text { TK } \\
5\end{array}$ & CCR & 10000 & $\begin{array}{c}\text { Fl } \\
251\end{array}$ & $\begin{array}{c}81 \\
4\end{array}$ & $\begin{array}{c}12: 20 p \\
\text { m }\end{array}$ & $2 \mathrm{pm}$ & 10000 \\
\hline
\end{tabular}


Table (8) Summary of intermediate tanks schedule for supper gasoline

\begin{tabular}{|c|c|c|c|c|c|c|c|}
\hline $\begin{array}{l}\text { Tan } \\
\text { k n. }\end{array}$ & $\begin{array}{c}\text { Compone } \\
\text { nt }\end{array}$ & $\begin{array}{c}\text { Start } \\
\text { period } \\
\text { invento } \\
\text { ry }\end{array}$ & $\begin{array}{c}\text { Flo } \\
\text { w } \\
\text { seq. }\end{array}$ & $\begin{array}{c}\text { Flo } \\
\text { w } \\
\text {.hr }\end{array}$ & $\begin{array}{l}\text { Startin } \\
\text { g time }\end{array}$ & $\begin{array}{l}\text { Endin } \\
\text { g } \\
\text { time }\end{array}$ & $\begin{array}{c}\text { End } \\
\text { period } \\
\text { invento } \\
\text { ry }\end{array}$ \\
\hline $\begin{array}{c}\text { TK } \\
1\end{array}$ & $\begin{array}{c}\text { Light } \\
\text { naphtha }\end{array}$ & 10000 & $\begin{array}{c}\text { Fl } \\
311\end{array}$ & 0 & $\begin{array}{c}10: 35 a \\
\text { m }\end{array}$ & $11 \mathrm{am}$ & 16304 \\
\hline $\begin{array}{c}\text { TK } \\
2\end{array}$ & $\begin{array}{l}\text { Power } \\
\text { former }\end{array}$ & 10000 & $\begin{array}{c}\text { Fl } \\
321\end{array}$ & $\begin{array}{c}74 . \\
8\end{array}$ & $\begin{array}{c}\text { 10:35a } \\
\text { m }\end{array}$ & $11 \mathrm{am}$ & 10000 \\
\hline $\begin{array}{c}\text { TK } \\
3\end{array}$ & Isomerat & 10000 & $\begin{array}{c}\text { Fl33 } \\
1\end{array}$ & $\begin{array}{c}120 \\
0\end{array}$ & $\begin{array}{c}\text { 10:35a } \\
\text { m }\end{array}$ & $11 \mathrm{am}$ & 10000 \\
\hline $\begin{array}{c}\text { TK } \\
4\end{array}$ & reformat & 10000 & $\begin{array}{c}\text { Fl } \\
341\end{array}$ & $\mathbf{0}$ & $\begin{array}{c}\text { 10:35a } \\
\text { m }\end{array}$ & $11 \mathrm{am}$ & 10000 \\
\hline $\begin{array}{c}\text { TK } \\
5\end{array}$ & CCR & 10000 & $\begin{array}{c}\text { Fl } \\
351\end{array}$ & $\begin{array}{c}116 \\
2\end{array}$ & $\begin{array}{c}10: 35 a \\
\text { m }\end{array}$ & $11 \mathrm{am}$ & 10000 \\
\hline
\end{tabular}

Table (9) Summary of Product tanks schedule for two days

\begin{tabular}{|c|c|c|c|}
\hline $\begin{array}{c}\text { Product } \\
\text { name }\end{array}$ & $\begin{array}{c}\text { Tank } \\
\text { number }\end{array}$ & $\begin{array}{c}\text { End period } \\
\text { inventory } \\
\text { (first day ) }\end{array}$ & $\begin{array}{c}\text { End period inventory } \\
\text { (second day) }\end{array}$ \\
\hline \multirow{2}{*}{ Regular } & TK6 & 50000 & 10000 \\
\hline \multirow{2}{*}{ Premium } & TK7 & 10000 & $\mathbf{5 0 0 0 0}$ \\
\cline { 2 - 4 } & TK8 & 14000 & 10000 \\
\hline \multirow{2}{*}{ Supper } & TK9 & 10000 & 14000 \\
\hline & TK10 & 11000 & 10000 \\
\hline
\end{tabular}




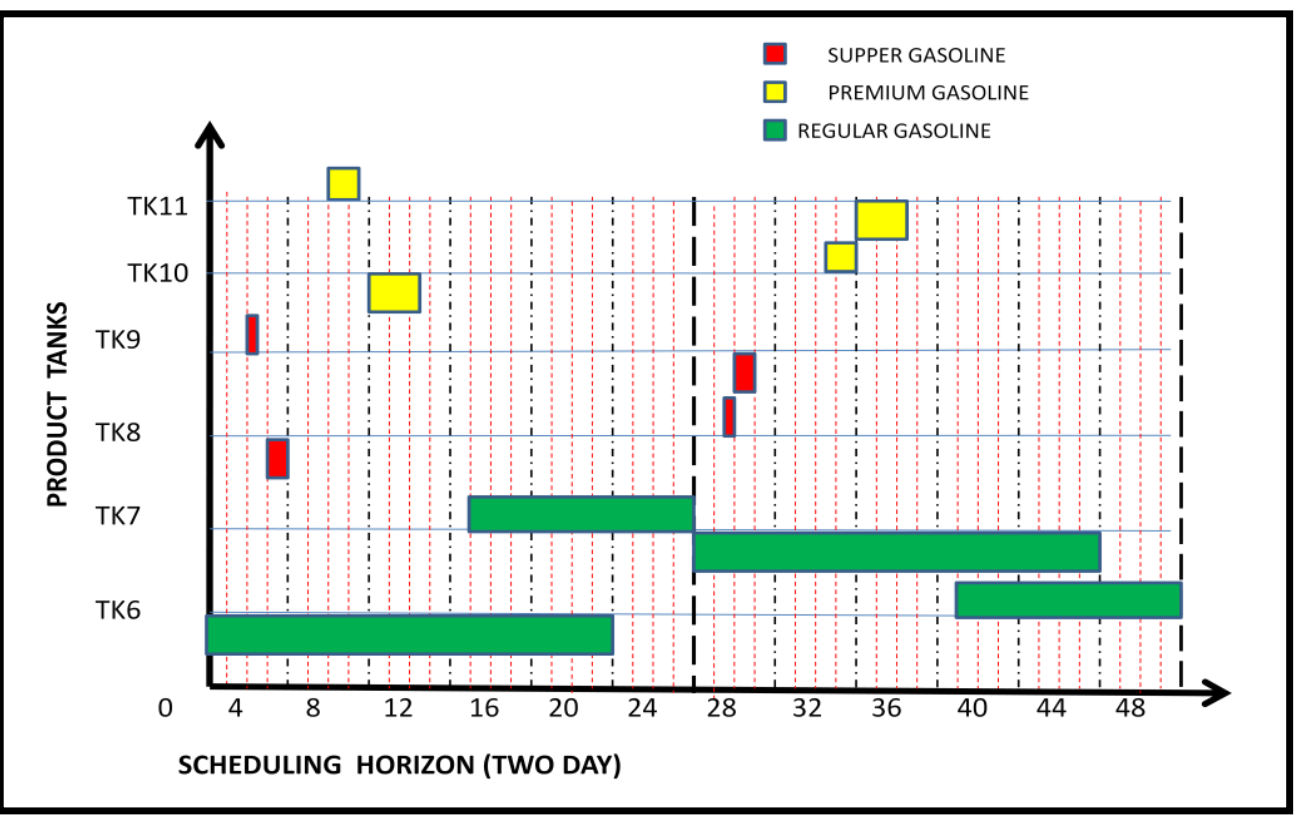

Fig. (9) Gantt chart scheduling for intermediate tanks

Table (10) summary for blender's schedule

\begin{tabular}{|r|r|r|r|r|r|}
\hline Blen & Product & $\begin{array}{r}\text { a } \\
\text { ders }\end{array}$ & $\begin{array}{c}\text { Starting } \\
\text { time }\end{array}$ & $\begin{array}{c}\text { Ending } \\
\text { time }\end{array}$ & $\begin{array}{c}\text { Product } \\
\text { quantity/ } \\
\text { barrel }\end{array}$ \\
\hline \multirow{2}{*}{ B1 } & $\begin{array}{r}\text { Regular } \\
\text { G. }\end{array}$ & 1 & $10 \mathrm{pm}$ & $8 \mathrm{am}$ & 40000 \\
\hline & $=$ & 2 & $10 \mathrm{pm}$ & $8 \mathrm{am}$ & 40000 \\
\hline \multirow{2}{*}{ B2 } & $\begin{array}{r}\text { Premium } \\
\text { G. }\end{array}$ & 1 & $12 \mathrm{pm}$ & $2 \mathrm{pm}$ & 4695 \\
\hline & $=$ & 2 & $12 \mathrm{pm}$ & $2 \mathrm{pm}$ & 4695 \\
\hline \multirow{2}{*}{ B3 } & Supper & 1 & $10: 19 \mathrm{am}$ & $11 \mathrm{am}$ & 1000 \\
\hline & G. & & & $11 \mathrm{am}$ & 1000 \\
\hline
\end{tabular}




\section{Conclusion And Futuer Recommendation}

In the current case the proposed approach employed to express the ability to produce regular and premium of gasoline without additives. If refinery produce supper grade of gasoline, this will generate surplus of intermediate products. Therefore to produce high grade of gasoline without additives and surplus in intermediate product, the refinery should include an additional conversion unit to improve the light naphtha of more than $95 \mathrm{ON}$ with capacity at least $5000 \mathrm{bpd}$.

The conclusions of this work are as follow:

1. The proposed approach avoids some assumptions that make the model unrealistic; therefore, the proposed approach is applicable in real world.

2. For the complex case study the results of the proposed approach (LP \& MILP model) were gained after $1^{\text {st }}$ Iraq Oil \& Gas Conference ( $1^{\text {ST }}$ IOGC)
0.031 second CPU time for planning level and after 3.375 second CPU time for scheduling level.

3. The current work was applied to gasoline product and fuel oil, but can also be applied for all blended refinery products like gas oil, lubricants, jet fuel etc...

4. The proposed approach has the ability to assess the financial risk that occurs by uncertain inputs.

5. The proposed approach utilizes the Linear Goal Programming (LGP) and Linear Programming (LP) efficiently.

6. The developed approach has high efficiency and flexibility for shortterm planning and scheduling in oil refinery.

7. The proposed approach minimize lead time by reduce reblend process . 
It's a continuation to this work, the followings are recommendation:

1. The number of grades of some products may exceed 18 types in AL-Dura refinery, therefore, when utilizing the proposed approach the developments of the scheduling level are necessary to impose the sequencing in the blender to produce different products.

2. For a company like MRC that has many demand areas and many refineries. It is important to integrate a network for product blending and distribution to minimize the bottleneck in some refineries therefore model for multi refineries planning is needed.

3. Uncertainty becomes a common aspect therefore, integrating crude supply, blending, and a product distribution model in refinery planning under uncertainty is needed.

4. Integrating the related process is necessary to avoid the financial risk generated by the decomposing; therefore, financial risk management in the scheduling of refinery operations.

5. Inventory problem has grown recently in AL-Dura Refinery according to development process therefore it's important to study inventory management under uncertainty. 


\section{$\underline{\text { Refernces }}$}

1. Ming Li Qiqiang, Tian Xin , (2009) Scheduling Optimization of Refinery Operations Based on Production Continuity, Proceedings of the IEEE International Conference on Automation and Logistics Shenyang, China Vol 55--PP4244-4795

2. Dayadeep S. Monder, (2001) Real-Time Optimization of Gasoline Blending with Uncertain Parameters . MSc. Thesis. University of Alberta, Canada .

3. Cuiwen Cao a, Xingsheng Gu a, (2009) Chance Constrained Programming Models for Refinery Short-term Crude Oil Scheduling Problem, App. Math. Mod,Vol. 33,PP. 1696-1707.

4. J. D. Kelly , (2006) Logistics: the Missing Link In Blend Scheduling Optimization, .Hydrocarbon Processing, pgs $45-51$.

5. Hansa Lakkhanawat, Miguel J. Bagajewicz, . (2008) Financial Risk Management with Product Pricing in the Planning of Refinery Operations Ind. Eng. Chem. Res, Vol 47, pp. 6622-6639.

6. J. Hancsok , Sz. Magyar, and Valkai, (2009) Investigation of the Production of Gasoline Blending Component Free of Sulfur. petr. \& and coal, Vol. 45, PP. 3-4, 99-104.

7. Klaus Glismann, \&Gu" nter Gruhn, (2001)Integrated Planning and Scheduling for Blending Processes. Comp. \& Chem. Eng. Vol. 20.pp. 109128

8. Rois Fatoni,(2009) Modeling and Optimization of Refinery Gasoline Blending Ind. Eng. Chem. Res, Vol 50 ,PP. 4475-4482

9. Cheng Seong Khor, (2006) A Hybrid of Stochastic Programming Approaches with Economic and Operational Risk Management for 
Petroleum Refinery Planning under Uncertainty, MSc. Thesis, Waterloo, Ontario, Canada,

10.Arkadej Pongsakdi , (2006) Pramoch , and Miguel J. Bagajewicz, Financial Risk Management in the planning of refinery operations, Int. J. Pro.\& Eco. Vol.103, PP. 64-86.

11.Khalid Y. Al-Qahtani, (2009). Petroleum Refining and Petrochemical Industry Integration and Coordination under Uncertainty. PhD Dissertation University of Waterloo, Canada.

12.Naiqi WU, MengChu Zhou , (2005) Short-term Scheduling for Refinery Process: Bridging the Gap between Theory and Applications, international journal of intelligent control and system. Vol. 10, No. 2, pp. 162-174.

13.Khalid Y. AL-Qahtani and Ali Elkamel , (2010) "Planning and Integration of Refinery and Petrochemical Operations", Wiley-vch Verlag GmbH \& Co. KGaA, Weinheim .

14.James H. Gary Glen, (2007) E. Hadwerk Mark, "Petroleum Refining Technology and Economic, CRC press, Fifth edition. USA.

15.Zukui Li, (2010) Process Operations with Uncertainty and Integration Considerations, PhD Dissertation, The State University of New Jersey, USA

16.Surinder Parkash , (2003) "Refining Process Handbook" Gulf Professional Publishing of Elsevier, USA. Second edition.

17.Edward C. bodington, , (1995) "Planning Scheduling and Control integration in the process industry" McGraw-Hill, USA. 


\section{APPENDIX A}

Combined Report for product scheduling

04:11:37

Sunday July $\quad 03 \quad 2011$

$\begin{array}{llll}\text { Decision } & \text { Solution } & \text { Unit Cost or } & \text { Total }\end{array}$

Basis

\begin{tabular}{|c|c|c|c|c|c|c|}
\hline \multicolumn{3}{|c|}{ Variable } & \multirow{2}{*}{$\begin{array}{r}\text { Profit c(j) } \\
6,240.0000\end{array}$} & \multirow{2}{*}{$\begin{array}{c}\text { Contribution } \\
34,406,320.0000\end{array}$} & \multirow{2}{*}{$\begin{array}{l}\text { Cost } \\
0\end{array}$} & \multirow{2}{*}{$\begin{array}{l}\text { Status } \\
\text { basic }\end{array}$} \\
\hline 1 & X111 & $5,513.8330$ & & & & \\
\hline 2 & X121 & $7,528.6040$ & $4,680.0000$ & $35,233,870.0000$ & 0 & basic \\
\hline 3 & X131 & $10,000.0000$ & $3,432.0000$ & $34,320,000.0000$ & 0 & basic \\
\hline 4 & X141 & $5,000.0000$ & $2,964.0000$ & $14,820,000.0000$ & 0 & basic \\
\hline 5 & X151 & $11,957.5600$ & $1,560.0000$ & $18,653,790.0000$ & 0 & basic \\
\hline 6 & X211 & 0 & $6,708.0000$ & 0 & -737.8469 & at bounc \\
\hline 7 & $\times 221$ & $2,471.0530$ & $5,148.0000$ & $12,720,980.0000$ & 0 & basic \\
\hline 8 & $\times 231$ & 0 & $3,900.0000$ & 0 & 0 & basic \\
\hline 9 & X241 & 0 & $3,432.0000$ & 0 & -73.5947 & at \\
\hline \multicolumn{7}{|c|}{ bound } \\
\hline 10 & $X 251$ & $2,223.9470$ & $2,028.0000$ & $4,510,165.0000$ & 0 & basic \\
\hline 11 & X311 & 181.8180 & $7,332.0000$ & $1,333,090.0000$ & 0 & basic \\
\hline 12 & X321 & 0 & $5,772.0000$ & 0 & 0 & basic \\
\hline 13 & X331 & 0 & $4,524.0000$ & 0 & 0 & basic \\
\hline 14 & X341 & 0 & $4,056.0000$ & 0 & 0 & basic \\
\hline 15 & X351 & 818.1818 & $2,652.0000$ & $2,169,818.0000$ & 0 & basic \\
\hline 16 & X112 & $5,513.8310$ & $6,240.0000$ & $34,406,300.0000$ & 0 & basic \\
\hline 17 & X122 & $7,528.6100$ & $4,680.0000$ & $35,233,900.0000$ & 0 & basic \\
\hline 18 & X132 & $10,000.0000$ & $3,432.0000$ & $34,320,000.0000$ & $\mathbf{0}$ & basic \\
\hline
\end{tabular}

$1^{\text {st }}$ Iraq Oil \& Gas Conference ( $1^{\text {ST }}$ IOGC) 


\begin{tabular}{|c|c|c|c|c|c|c|c|}
\hline 19 & $\mathrm{X} 142$ & $5,000.0000$ & $2,964.0000$ & $14,820,000.0000$ & \multicolumn{2}{|l|}{0} & basic \\
\hline 20 & X152 & $11,957.5600$ & $1,560.0000$ & $18,653,790.0000$ & \multicolumn{2}{|l|}{0} & basic \\
\hline 21 & X212 & 0 & $6,708.0000$ & 0 & \multicolumn{2}{|l|}{-738.9474} & at \\
\hline \multicolumn{8}{|c|}{ bound } \\
\hline 22 & X222 & $2,471.0530$ & $5,148.0000$ & $12,720,980.0000$ & \multicolumn{2}{|l|}{0} & basic \\
\hline 23 & $X 232$ & 0 & $3,900.0000$ & 0 & \multicolumn{2}{|l|}{0} & basic \\
\hline 24 & $X 242$ & 0 & \multirow[t]{2}{*}{$3,432.0000$} & 0 & \multicolumn{2}{|l|}{-73.8947} & at \\
\hline \multicolumn{7}{|c|}{ bound } & \\
\hline 25 & $\times 252$ & $2,223.947$ & $2,028.0000$ & $4,510,165.0000$ & \multicolumn{2}{|l|}{0} & basic \\
\hline 26 & X312 & 181.8180 & $7,332.0000$ & $1,333,090.0000$ & \multicolumn{2}{|l|}{0} & basic \\
\hline 27 & X322 & 0 & $5,772.0000$ & 0 & \multicolumn{2}{|l|}{0} & basic \\
\hline 28 & X332 & 0 & $4,524.0000$ & 0 & 0 & basic & \\
\hline 29 & X342 & 0 & $4,056.0000$ & 0 & 0 & basic & \\
\hline 30 & X352 & 818.1818 & $2,652.0000$ & $2,169,818.0000$ & 0 & basic & \\
\hline 31 & y11 & $40,000.0000$ & 0 & 0 & 0 & basic & \\
\hline 32 & y21 & $4,695.0000$ & 0 & basic & & & \\
\hline 33 & y31 & 999.9998 & 0 & basic & & & \\
\hline 34 & y12 & $40,000.0000$ & 0 & basic & & & \\
\hline 35 & $y 22$ & $4,695.0000$ & 0 & basic & & & \\
\hline 36 & y32 & 999.9998 & 0 & basic & & & \\
\hline 37 & VJ11 & $16,304.3500$ & 0 & basic & & & \\
\hline 38 & VJ21 & $10,000.3400$ & 0 & basic & & & \\
\hline 39 & VJ31 & $10,000.0000$ & 0 & basic & & & \\
\hline 40 & VJ41 & $10,000.0000$ & 0 & basic & & & \\
\hline 41 & VJ51 & $10,000.3100$ & 0 & basic & & & \\
\hline
\end{tabular}




\begin{tabular}{|c|c|c|c|c|c|c|}
\hline 42 & VJ12 & $22,608.7000$ & 0 & 0 & 0 & basic \\
\hline 43 & VJ22 & $10,000.6800$ & 0 & 0 & 0 & basic \\
\hline 44 & VJ32 & $10,000.0000$ & 0 & 0 & 0 & basic \\
\hline 45 & VJ42 & $10,000.0000$ & 0 & 0 & 0 & basic \\
\hline 46 & VJ52 & $10,000.6200$ & 0 & 0 & 0 & basic \\
\hline 47 & FL111 & 553.3364 & 0 & 0 & 0 & basic \\
\hline 48 & FL121 & 755.5338 & 0 & 0 & 0 & basic \\
\hline 49 & FL131 & $1,003.5670$ & 0 & 0 & 0 & basic \\
\hline 50 & FL141 & 501.7834 & 0 & 0 & 0 & basic \\
\hline 51 & FL151 & $1,200.0000$ & 0 & 0 & 0 & basic \\
\hline 52 & FL211 & 0 & 0 & 0 & 0 & at bound \\
\hline 53 & FL221 & $1,200.0000$ & 0 & 0 & 0 & basic \\
\hline 54 & FL231 & 0 & 0 & 0 & 0 & at bound \\
\hline 55 & FL241 & 0 & 0 & 0 & 0 & at bound \\
\hline 56 & FL251 & $1,080.0010$ & 0 & 0 & 0 & basic \\
\hline 57 & FL311 & 266.6563 & 0 & 0 & 0 & basic \\
\hline 58 & FL321 & 0 & 0 & 0 & 0 & at bound \\
\hline 59 & FL331 & 0 & 0 & 0 & 0 & at bound \\
\hline 60 & FL341 & 0 & 0 & 0 & 0 & at bound \\
\hline 61 & FL351 & $1,200.0000$ & 0 & 0 & 0 & basic \\
\hline 62 & FL112 & 553.3363 & 0 & 0 & 0 & basic \\
\hline 63 & FL122 & 755.5341 & 0 & 0 & 0 & basic \\
\hline 64 & FL132 & $1,003.5670$ & 0 & 0 & 0 & basic \\
\hline 65 & FL142 & 501.7834 & 0 & 0 & 0 & basic \\
\hline
\end{tabular}




\begin{tabular}{|c|c|c|c|c|c|c|}
\hline 66 & FL152 & $1,200.0000$ & 0 & 0 & 0 & basic \\
\hline 67 & FL212 & 0 & 0 & 0 & 0 & at bound \\
\hline 68 & FL222 & $1,200.0000$ & 0 & 0 & 0 & basic \\
\hline 69 & FL232 & 0 & 0 & 0 & 0 & at bound \\
\hline 70 & FL242 & 0 & 0 & 0 & 0 & at bound \\
\hline 71 & FL252 & $1,080.0010$ & 0 & 0 & 0 & basic \\
\hline 72 & FL312 & 266.6563 & 0 & 0 & 0 & basic \\
\hline 73 & FL322 & 0 & 0 & 0 & 0 & at bound \\
\hline 74 & FL332 & 0 & 0 & 0 & 0 & at bound \\
\hline 75 & FL342 & 0 & 0 & 0 & 0 & at bound \\
\hline 76 & FL352 & $1,200.0000$ & 0 & 0 & 0 & basic \\
\hline 77 & VI11 & $50,000.0000$ & 0 & 0 & 0 & basic \\
\hline 78 & VI21 & $10,000.0000$ & 0 & 0 & 0 & basic \\
\hline 79 & VI31 & $14,695.0000$ & 0 & 0 & 0 & basic \\
\hline 80 & VI41 & $10,000.0000$ & 0 & 0 & 0 & basic \\
\hline 81 & VI51 & $11,000.0000$ & 0 & 0 & 0 & basic \\
\hline 82 & VI61 & $10,000.0000$ & 0 & 0 & 0 & basic \\
\hline 83 & VI12 & $10,000.0000$ & 0 & 0 & 0 & basic \\
\hline 84 & VI22 & $50,000.0000$ & 0 & 0 & 0 & basic \\
\hline 85 & VI32 & $10,000.0000$ & 0 & 0 & 0 & basic \\
\hline 86 & VI42 & $14,695.0000$ & 0 & 0 & 0 & basic \\
\hline 87 & VI52 & $10,000.0000$ & 0 & 0 & 0 & basic \\
\hline 88 & VI62 & $11,000.0000$ & 0 & 0 & 0 & basic \\
\hline 89 & K11 & 1.0000 & 0 & 0 & 0 & at bound \\
\hline 90 & K21 & 1.0000 & 0 & 0 & 0 & at bound \\
\hline
\end{tabular}

$1^{\text {st }}$ Iraq Oil \& Gas Conference ( $1^{\text {ST }}$ IOGC) 


\begin{tabular}{|c|c|c|c|c|c|c|}
\hline 91 & K31 & 1.0000 & 0 & 0 & \multicolumn{2}{|c|}{ at bound } \\
\hline 92 & K12 & 1.0000 & 0 & 0 & \multicolumn{2}{|c|}{ at bound } \\
\hline 93 & K22 & 1.0000 & 0 & 0 & \multicolumn{2}{|c|}{ at bound } \\
\hline 94 & K32 & 1.0000 & 0 & 0 & 0 & at bound \\
\hline 95 & SL1 & $2,347.6280$ & 1.0000 & $2,347.6280$ & 0 & basic \\
\hline 96 & SL2 & 715.0095 & 1.0000 & 715.0095 & 0 & basic \\
\hline 97 & SL3 & $1,323.8200$ & 1.0000 & $1,323.8200$ & 0 & basic \\
\hline 98 & A11 & 1.0000 & 0 & 0 & 0 & at bound \\
\hline 99 & A21 & 1.0000 & 0 & 0 & 0 & at bound \\
\hline 100 & A31 & 1.0000 & 0 & 0 & 0 & basic \\
\hline 101 & A12 & 1.0000 & 0 & 0 & 0 & at bound \\
\hline 102 & A22 & 1.0000 & 0 & 0 & 0 & at bound \\
\hline 103 & A32 & 1.0000 & 0 & 0 & 0 & basic \\
\hline 104 & N1 & 3.0000 & 0 & 0 & 0 & basic \\
\hline 105 & N2 & 3.0000 & 0 & 0 & 0 & basic \\
\hline
\end{tabular}

Objective Function $\quad($ Max. $)=316,340,400.0000$ 


\section{$\underline{\text { Nomenclature }}$}

\section{$\underline{\text { Indices }}$}

d due dates of product demands

j intermediate product (component)

i final products or gasoline grades

t time slots

p penalty

s product tank

z component tank

Sets

$\mathrm{D}=$ set of product due dates

$J=$ set of intermediates or components to be blended

$I=$ set of final products

$T=$ set of time slots

$P=$ set of penalties

$S=$ set of product tanks

$\mathrm{Z}=$ set of component tanks

Parameters

$\mathrm{PF} \mathbf{j}=$ profit of component $\mathbf{j}$.

PFi = profit of product $i$.

$\mathrm{d} t=$ demand due date in time slot $t$.

dd ih $=$ the required demand for product $\mathbf{i}$ at time horizon $H$.

dd it $=$ the required demand for product $i$ at time slot $t$.

ddcih $=$ minimum demand must be satisfy at time horizon $h$.

$1^{\text {st }}$ Iraq Oil \& Gas Conference ( $1^{\text {st }}$ IOGC) 
ddcit $=$ minimum demand must be satisfy at time slot $\mathbf{t}$

cpijt= component percentage in product $i$.

et $=$ duration of time slot $\mathrm{t}$.

$\mathrm{Fj}=$ constant flow rate of components from production units.

$\mathrm{H}$ = time horizon.

$\mathrm{AV} j h=$ availability of component $j$ in time horizon $h$.

AV $j t=$ availability of component $j$ in time $t$.

Fllmax it $=$ maximum flow rate of product $i$.

Fllmin it $=$ minimum flow rate of product $i$.

Flmax $\mathbf{j}=$ maximum component $\mathbf{j}$ flow rate required to produce product $\mathbf{i}$ in due date $t$.

Flmin $\mathbf{j}=$ minimum component $\mathbf{j}$ flow rate required to produce product $\mathbf{i}$ in due date Qi= the required property for product $i$

$q . j=$ the required property for component $\mathbf{j}$

$\operatorname{con} j, i=$ volumetric amount of component $\mathbf{j}$ in product quantity .

$s t=$ predefined starting time of time slot $t$.

$V \max j z t=$ maximum storage capacity of component $j$ in tank $\mathrm{z}$ at time $t$.

$V \min j z t=$ minimum storage capacity of component $j$ in tank $z$ at time $t$.

Vmax ist $=$ maximum storage capacity of product $I$ in tank $s$ at time $t$.

Vmin i st $=$ minimum storage capacity of product $i$ in tank $s$ at time $t$.

pltysj= penalty cost for purchasing or selling component $\mathbf{j}$ from third party.

Pltydit =penalty cost for unsatisfied demand for product $i$.

\section{Binary Variables}

Ait $=$ binary variable denoting that product $\mathbf{i}$ is blended in time slot $t$ 
Kist $=$ binary variable denoting that product $i$ is lifted form tank $s$ in time $t$

\section{Integer variable}

$\mathrm{N} b t=$ maximum number of blenders that can be working in parallel in time slot $t$.

\section{Continues Variables}

xijh = amount of volumetric quantity of component $\mathbf{j}$ being transferred to produce product $i$ at time horizon $h$.

xijt $=$ amount of volumetric quantity of component $\mathbf{j}$ being transferred to produce product $\mathrm{i}$ at time slot $\mathrm{t}$.

yih= amount of volumetric quantity of product $\mathrm{i}$ being blended in time horizon $\mathrm{h}$.

yit= amount of volumetric quantity of product $i$ being blended in time $t$.

ini $j z t=$ initial inventory of component $\mathbf{j}$ in $\operatorname{tank} z$ at event point $t$.

ini ist = initial inventory of product $I$ in tank $s$ at event point $t$.

$S j t=\operatorname{amount}$ of component $j$ to be purchased or sold in time slot $t$.

$D d-i t=$ amount of product purchase product from third party to satisfy demand

$D d+i t=$ amount of surplus product $i$ at time slot $t$.

Sh= surplus of the available component $\mathbf{j}$ at time horizon $\mathbf{h}$.

SLjt $=$ slack variable for component flow rate at time slot $t$.

SLLit= slack variable for product quantity at time slot $t$.

MADgh = goal deviation to minimize unsatisfied goal at time horizon $h$.

$\mathrm{MIDgh}=$ goal deviation to maximizes unsatisfied goal at time horizon $\mathbf{h}$.

Fljz $t=$ target flow for component $j$ from tank $z$ at time slot $t$.

Fllist=target flow for product $\mathrm{i}$ from tank $\mathrm{s}$ at time slot $\mathrm{t}$. 